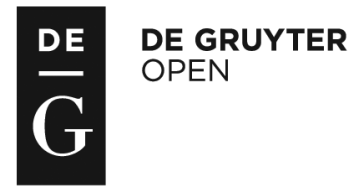

Administration, vol. 64, no. 2 (2016), pp. 61-83

doi: 10.1515/admin-2016-0016

\title{
Lessons from abroad: Rebalancing accountability and pedagogy in the Irish social care sector through the use of effective leadership
}

\author{
Cathy Jones \\ Department of Applied Social Sciences, Limerick Institute of Technology \\ Catherine Smey Carston \\ Department of Child Studies and Social Work, Mount Royal University, \\ Calgary
}

\begin{abstract}
A concern is emerging in Ireland that social care managers and staff are moving too far away from the 'care' in social 'care' work. In this paper a discussion of the impact of the bureaucratic procedures and regulation within the social work and social care work sectors is presented along with an exploration of leadership approaches. It is argued that certain leadership approaches, in particular pedagogical leadership, could not only help social care managers to negotiate the complex issues they are facing but also facilitate putting the 'care' back into social 'care' work. Pedagogical leadership is globally supported across a variety of human service disciplines: it facilitates the creation of a learning culture within the workplace where social care managers facilitate conversations with their teams to encourage reflection, critical thinking and contributions to the professional wisdom required for quality service. The purpose of this article is to contribute to the dialogue within leadership practice for social care professionals. This discourse is necessary if lessons are to be learned from past experiences in this country and others about how to balance the need for care, learning and compassion with accountability.
\end{abstract}


Keywords: Pedagogical leadership, over-bureaucratisation, social care work, Ireland

\section{Introduction}

The food would be cold and would be given to her on a piece of plastic while she was tied up in the bath. She would eat it like a dog, pushing her face to the plate. Except that of course a dog is not usually tied up in a bag full of its own excrement. To say that Kouao and Manning treated her like a dog would be wholly unfair, she was treated worse than a dog. (Laming, 2003, p. 1)

On 12 January 2000 in the UK, Victoria Climbié's great-aunt MarieTherese Kouao and Carl John Manning were convicted of her murder. In April 2001 Lord Laming and his inquiry team were appointed by the Secretary of State for Health and the Secretary of State for the Home Department to conduct three statutory inquiries to find out why the response of social services was not adequate to prevent Victoria's death. Together, these reviews became known as the Victoria Climbié Inquiry.

Victoria was known to two housing authorities, four social services departments, two child-protection teams of the Metropolitan Police Service and a specialist centre of the National Society for the Prevention of Cruelty to Children, and had been admitted to two separate hospitals because of suspected deliberate harm. Laming testified that Victoria's death was a gross failure of the system and was inexcusable. He proposed that the main reasons for this failure rested with those responsible for service delivery - the managers within the social professions. He stated that a leader's performance and effectiveness should be judged against the delivery of quality services to children and families, rather than the maintenance of bureaucratic procedures (Laming, 2003).

The inquiry insisted that strong leaders who engage their teams in continuous examination to achieve quality outcomes for children and families, together with effective decision-making, must replace bureaucratic administration (Laming 2003). Thom Garfat (2001), Canadian professor and researcher in social care practice, recommends that it is important for the international community of practitioners to talk about what we know, share what we do and struggle together to find new solutions for the benefit of children, 
youth and families. As collaborating authors, we embraced this suggestion and began the dialogue about how to rebalance the trend towards bureaucracy through the use of effective leadership. Although this challenge is common within many countries' systems, this paper will examine the professionalisation era of Irish social care in the twenty-first century, and then present leadership approaches that may be effective for those managing and working within these regulatory and legislative changes.

Various leadership strategies that have been effective globally, such as transformational, situational and pedagogical approaches, will be examined. This last approach to leadership has been explored within social service and education disciplines globally, and has resulted in effective change (Baxter et al., 2014; Male \& Palaiologou, 2012; O'Donovan, 2015), positing a possible solution for social care leaders who wish to strike a better balance between relationship-based care, staff support and accountability in Irish practice.

A number of reports in the UK (Francis, 2013; Laming, 2003; Munro, 2010; 2011) point to the need for leadership development for those who provide social care services. These inquiries lay the issue of accountability over pedagogy, which, in the absence of strong leadership, has at times led to neglect and unethical practice.

\section{Twenty-first century developments in the Irish social care sector}

The field of social care has expanded considerably in recent years, far outgrowing its origins in residential child care. It has evolved out of a set of loosely linked practices in environments such as community childcare, targeted youth work, residential childcare and community project work (Lalor \& Share, 2009). During the past twenty to thirty years, there has also been a growing separation of the state from the church, one of the first factors that influenced new management structures in social care (McCarthy, 2006). Social care services in contemporary Ireland are delivered by a variety of public, for-profit and non-profit agencies. Administrative and legal responsibility for most of the publicly delivered services now rests with the Health Service Executive (HSE) and Tusla, with the government departments responsible for education and justice also having a role (Howard, 2014). Within the public, for-profit and non-profit social care services, almost 8,000 social care workers are employed (Skills and Labour Market Research Unit, 2009). 
In recent times, in both Ireland and the UK, there have been moves to explicitly regulate the social care field through legislation and regulation. The Child Care Act, 1991, provided for a new regulatory model for care services for children. In 1993 the publication of the Kilkenny Incest Report and the Madonna House Report led to tighter procedures for managers in terms of Garda vetting, reporting abuse and monitoring with the Social Services Inspectorate (SSI), as well as a much greater focus on children's rights (McCarthy, 2006).

Further legislative developments in 2005, such as the Health and Social Care Professionals Act, allowed for the registration and regulation of health and social care professions, including social care work. In 2009 the Commission to Inquire into Child Abuse (Ryan report) made numerous recommendations, including the need to review national childcare policy, regular provision and inspection of all services relating to children, accountability for the quality of the service, the importance of clear communications and the consistent implementation of Children First guidelines throughout the state in dealing with allegations of abuse (Commission to Inquire into Child Abuse, 2009). According to Howard (2012), the Ryan report was a landmark publication, which exposed a litany of poor management, collusion and systemic abuse. However, while Irish reports such as the Madonna House Report, the Kennedy Incest Report, the Ryan report and reports by the Office of Ombudsman for Children have all stated that major reform was required within social care services to not only manage risk but also improve quality and consistency for children and families, Burns \& McCarthy (2012, p. 26) note that change following these reports has been 'glacially slow'.

In 2010 the three professional associations, the Irish Association of Social Care Workers, the Irish Association of Social Care Managers and the Irish Association of Social Care Educators, amalgamated under the umbrella title of Social Care Ireland. This association was officially launched in 2011 and, while the three bodies still meet separately, this marked an important step in an attempt to consolidate roles and provide consistent professional development for its members.

These evolving governance and management structures in social care work present a challenging workplace environment for staff and managers alike (McCarthy, 2006). The various legislative changes that have occurred in the last two to three decades have led to a context where accountability and the rights of service users are a strong priority (McCarthy, 2006). Although these tenets are critical to 
effective social care practice, we suggest that managers also need to prioritise leadership and pedagogical practice to facilitate the interpretation and application of policy to practice for the workforce.

\section{Influences upon the regulation and professionalisation of Irish social care work}

The Irish social care and health system has witnessed two key developments in recent years, namely the establishment of the Health Information and Quality Authority (HIQA) and CORU under the Health and Social Care Professionals Act, 2005.

\section{Health Information and Quality Authority}

The regulatory body in social care that replaced the preceding SSI is HIQA, created under the Health Care Act in 2007. The purpose of this body is to monitor the standard of services for children, the elderly and those with disabilities within the social care arena. Previously mentioned reports published in the 1990s influence the work of HIQA with regard to child-protection procedures, standardised processes and accountability. HIQA has promoted developments in relation to audit, quality assurance, inspection and efficiency (Featherstone et al., 2012).

HIQA's role is to inform the public of what they can expect from services, and it has statutory powers to inspect and register services. The inspectors visit premises to assess the quality, safety and accountability of each service. The framework HIQA utilises for assessing standards within the services is based on six themes. The first two themes relate to the dimension of quality, and the other four themes relate to areas of capacity and capability. Taking children's services as an example, the dimensions of quality look at the childcentredness of services and the safety and effectiveness of those services. These dimensions depend upon services having capability and capacity in four key areas, namely leadership, resources, recruitment, and information to monitor and improve care (HIQA, 2010).

Increasing demands are now placed on managers to achieve and maintain a quality service (Featherstone et al., 2012). They are required to carry out self-assessments, provide data for analysis and submit documents for review, as well as prepare for visits by inspectors (Killeen, 2014). Whilst HIQA has generated positive change for service users and for public trust (Killeen, 2014), the questions being 
posed in this paper are: have the regulators overburdened social care workers with bureaucratic procedures that are getting in the way of good-quality 'relationship-based' practice, and can alternative leadership approaches bring the 'care' back into social care?

\section{CORU - Social Care Workers Registration Board}

Alongside HIQA, another important development was initiated in 2015, when the Minister for Health confirmed the establishment of the Social Care Workers Registration Board within CORU, under the Health and Social Care Professionals Act, 2005 (as amended), to regulate the profession of social care workers. The primary remit of CORU is to protect the public. Its role is to set the minimum standards that health and social care professionals must meet.

Since its inception, CORU has processed complaints against registered health and social care professionals within their fitness-topractise standards. Therefore, managers in the social care sector need to be well equipped with a solid grounding in these legal and regulatory frameworks, and be aware of the processes involved in the complaints system, as well as the requirements for registration.

\section{The changing nature and governance of services}

The following trends in the type of governance and funding mechanisms within social care services have also been evolving in Ireland. Firstly, within disability services, there has been a movement away from service provision towards support provision with increased individualised funding. The HSE report Time to Move on from Congregated Settings: A Strategy for Community Inclusion (2011) marked a recognition of the need for change in options for people with disabilities. Managing this role, and the complexities of individualised funding arrangements, will be a key element of the management function into the future (Davis \& Mullender, 1993; National Disability Authority, 2011). This will require managers to facilitate their own and their staff's learning about initiatives in care provision and clear assessments of risk while supporting quality interventions and true social inclusion and citizenship (Killeen, 2014).

Population ageing is also driving many countries to review health and social care policies (Moyle et al., 2013). If trends continue, the number of people aged over sixty-five in Ireland will double within the next twenty years (Department of Health, 2011). In recent years there has been a steady rise in the employment of social care workers within 
the HSE, the voluntary sector and private market-based services for older people (Barry \& Conlon, 2010). The social care model is holistic, promotes independence and uses non-medical interventions as far as possible. Hence, to counterbalance the impact of increased regulations in the sector, managers will need to facilitate pedagogical discussions among staff, to make real the language of the 'Third Age' (Gallagher \& Kennedy, 2003).

It is within the context of all of these twenty-first century developments that the need to discuss the polarities between bureaucracy and increased regulation and care arises. The potential opportunity to re-evaluate our priorities and the urgency to create a reflective space in our work were reinforced by Mark Smith in his address at the 2016 Social Care Ireland conference (Smith, 2016).

\section{Increasing concerns in Ireland about the impact of bureaucratisation}

Smith (2016) fears that mandatory registration of social care workers will see Irish services following the practice in Scotland, where, he argues, too much faith is being placed on systems in social care settings rather than people. He reminds us of the complexity of relationships in practice, in particular the importance of young people in care settings experiencing love and connectedness. These dimensions, he claims, are difficult to account for and acknowledge in measurable sets of standards (Smith, 2016). In 2010 the Department of Children, Schools and Families in the UK noted that, even with standards in place, it was the quality of the relationships that determined whether the child felt cared for on a day-to-day basis.

Forming secure and trusting relationships with clients is crucial in social care work, as the practice frequently takes place within the life space of the person (Lalor \& Share, 2013). In residential settings, for example, day-to-day shared life experiences are an important aspect of social care practice, and for many practitioners these moments are a key defining factor in their work. Hence, relationship-based practice within social care often takes place in a relatively informal, extended and intimate space (Lalor \& Share, 2009), and requires skill, deftness and professional wisdom on the part of the social care worker to use these moments as opportunities for therapeutic change.

For relationship-based practice to be fully realised in Ireland, practitioners require time to develop their reflective capabilities (Smith, 2016). However, with the reported increased paperwork 
burden on social care managers and their teams (Howard, 2014), this may be difficult to implement. Effective leadership will be required to support teams in order to create space for this essential dialogue within the services.

Dent \& Whitehead (2002) state that in all of the social professions there has been a loss of trust and a desire for a sense of order due to an increased perception of risk. This may be particularly the case in Ireland with the succession of high-profile failures in religious, medical, judicial and business arenas (Banks, 2007).

Improving quality and minimising risk has been a central issue for healthcare providers across the whole of Europe (Mendes \& Fradique, 2013). European literature describes a bureaucratic culture in the public sector with its strong emphasis on rules and regulations, where leaders are increasingly challenged to assume a central role in quality improvement and risk assessment (Mendes \& Fradique, 2013). Beresford (2014) states that face-to-face contact with Irish children and families is being compromised as staff are required to spend more time with paperwork to prove targets have been met. The Irish Association of Social Workers (2011) also proposes that this culture of managerialism, which has crept into the public sector, may be damaging rather than improving social work practice. Basu (2004) suggests that most social professionals rarely respond well to bureaucracy. Regulators, by their very nature, are positivist, reductionist and rationalist, whereas healthcare organisations tend to have collective leadership, with a unique professional culture that creates a shared set of social norms and values (Mesabbah \& Arisha, 2016).

Leaders within social care services therefore could be in a positive position to make improvements by promoting an open, transparent and safe culture where relationships and trust are paramount (Fenton 2015). Smith (2009) believes qualified, reflective, competent practitioners should not see themselves as victims of bureaucracy, but rather as leaders of reform who understand how the needs of children and ongoing development of staff can be maintained and enhanced. This can be achieved through examination of our pedagogical and relationship-based perspectives to gain a better understanding of our work and our responses to children in our care (Burck \& Cooper, 2007; Fenton, 2015).

Hence, it is argued that the last two decades have seen Irish and European social care services rapidly change in terms of regulation and accountability, and now more than ever innovative leadership is 
required to ensure that social care practice values (empathy, respect and advocacy) are recognised by those receiving the service within this increasingly bureaucratic environment (Mendes \& Fradique, 2013). To further support this argument, Mendes \& Fradique (2013) discovered that, within a healthcare setting, leadership actions such as recognition, communication, team development and innovation have a direct correlation with quality care. Workers who received this type of leadership responded by implementing caring, empathic and respectful interactions with patients. We need Irish discourse on 'leadership actions' in social care as well as in healthcare, to find ways of keeping 'quality practice' central to everything we do, so we avoid the recent experiences of the UK.

\section{Over-bureaucratisation in the UK}

The UK has experienced these effects across the public sector, with evidence documented in several recent enquiries such as the Munro Review (Munro, 2010; 2011) the Victoria Climbie Inquiry (Laming, 2003) and the inquiry into the Mid-Staffordshire NHS Trust (Francis, 2013).

The Munro Review of Child Protection (2010; 2011) was tasked with reviewing areas within the child-protection system that required reform. Some interesting findings emerged. It was suggested that the current managerialist-dominated model should be replaced with a model that provides local authorities with more freedom, where experienced staff could mentor junior front-line staff and where the excessive burden of inspection could be lifted. According to Munro (2010), safeguarding children and families in the UK had become overly dependent on procedures and paperwork, with front-line workers spending over 60 per cent of their time in front of computer screens. 'Helping children is a human process. When the bureaucratic aspects of work become too dominant, the heart of the work is lost' (Munro, 2011, p. 48).

The final report of the Munro Review (2011) made fifteen recommendations. These included moving from a compliance ethos to a learning culture and allowing those working in child protection to have more scope for professional judgement in deciding how to best support families and children. Munro (2010) argued that there are many people working in the sector who are eager to take on this leadership role and responsibility. These sentiments have been echoed by social work leaders in the Call for Change document published by the Irish Association of Social Workers (2011). 
Francis (2013) led an inquiry into the Mid-Staffordshire NHS Trust, which further supports Munro's (2010; 2011) views. This report highlighted the detrimental effects of a bureaucratic, target-driven system of management. Francis (2013) witnessed an institutional culture and leadership model that ascribed more importance to documenting positive information about the service rather than information capable of implying cause for concern. He reported that a wholly inadequate standard of care was provided, which failed to put patients at the centre of their work (Francis, 2013). He suggests a fundamental culture change is needed, beginning with leadership.

In 2013 the Health and Social Care Information Centre (HSCIC) in the UK was established. Their mandate was to reduce the collective burden associated with bureaucratic procedures and data collection. A 'busting bureaucracy' auditing campaign, involving several trusts, was developed. The audit confirmed that all staff spent up to 66 per cent of working time per week on bureaucracy. It also discovered that duplication of form-filling was one of the biggest burdens (HSCIC, 2014). Although this campaign was focused upon the health system, a similar audit in the Irish social care sector would be useful to ascertain the level of paperwork burden that exists for staff within the social care sector and whether the actual level of bureaucratic tasks is impeding upon the capacity for social care workers to build effective relationships with the people they work with.

Hence, many public inquiries have specifically highlighted that 'over-bureaucratisation' and failures in leadership have restricted the capacity to promote the paramountcy of quality outcomes and relationships in social care and social work (Francis, 2013; Laming, 2003; Munro, 2010; 2011). Each of these reports proposed radical new approaches to leadership in health and social care settings (Francis 2013; Laming, 2003; 2009; Munro, 2011). Therefore, making space for reflective practice and pedagogy through a combined model of leadership may provide a way for Irish social care managers to navigate their professional responsibilities.

There have been many discussions about the impact of increased bureaucracy upon the social professions, most notably the Irish Association of Social Workers' (2011) document A Call for Change. This document was in direct response to the HSE's proposed introduction of the Business Process Standardisation Project. Social workers indicated within this report that bringing in this traditional, bureaucratic, form-filling, deadline-based approach, with its focus on 
performance indicators, would not only fail to provide the answers to the crisis in child welfare but likely worsen the crisis (Irish Association of Social Workers, 2011).

The equivalent system in the UK, the Integrated Children's System and its associated Common Assessment Framework, was severely criticised by the Munro Review (2010). This system is now in the process of being dismantled in favour of an approach which recognises that professional knowledge and experience offer the greatest potential for effective, safe and quality practice. The Irish Call for Change report supports the necessity for social workers to prioritise relationship-building over paperwork and to access adequate supervision for high-quality provision (Irish Association of Social Workers, 2011). This call for a stronger focus on relationship-based practice is echoed within the social care profession (Smith, 2016).

According to the International Federation of Social Workers (2010), best practice internationally indicates that social workers should spend 70 per cent of their time in direct work with clients/ service users. This percentage directive could be extrapolated to social care work due to the similar reliance on relationship-based practice within the profession. However, Irish social workers state that they are spending a disproportionate amount of time at their desks completing paperwork, forms and reports (Irish Association of Social Workers, 2011). If this is the case within social care too, then it will severely impact relationship-building with clients, which is central to practice in both professions (Munro, 2011).

Fundamentally, the concern is that this increased regulation will lead to front-line social workers following rules rather than having the confidence to use their professional judgement in a situation. An important recommendation in the Victoria Climbie Inquiry was that practice should be governed by professional judgement, and not by rules and procedures (Laming, 2003). While regulation has its place, it cannot be a substitute for reflection, judgement and high-quality leadership (Laming, 2003).

Recent research by Mesabbah \& Arisha (2016), however, suggests there is some evidence that performance-management systems in today's public healthcare system in Ireland are moving to integrate non-financial standards with areas such as service quality, suggesting there may be a will to look at how strategies can best be deployed to enhance levels of communication and trust between management and practitioners. 


\section{Professionalisation, regulation and staff burnout}

At present, social care work is a complex system of evolving governance, funding and management structures, and will continue to present professional challenges for staff and managers. Significant administrative and legislative changes were identified as contributors to stress and burnout by Lloyd et al. (2002). This research also noted that 'working in a bureaucratic environment' was one of the top stressors due to the pressure in planning and meeting work targets (Lloyd et al., 2002, p. 258). Johnston et al. (2005) discovered that social care workers already experience above-average work-related stress compared to twenty-five other occupational groupings. Hence, the impact of 'over-bureaucratisation' may be compounded in social care work and lead to burnout.

Smyth et al. (2015) reported that contributory factors to burnout are role ambiguity (where there is uncertainty about the scope of the job and about the expectation of others), role conflict and a lack of influence over decision-making. Role ambiguity accounted for higher GHQ scores in a study with 1,276 social services staff (Balloch et al., 1998). Such ambiguity may have been heightened for social professionals in recent years given the marked changes in the regulation of service delivery and its discrepancy with relationshipbased practice.

Lenihan \& Sweeney (2010) suggest that management should place increased importance on recognising the early stages of burnout and develop appropriate intervention strategies, while Lloyd et al. (2002) state that quality supervision and team support are deemed to be protective factors to burnout. Professional supervision is at the heart of health and social care (Gray et al., 2010). As the chief executive officer of Skills for Care and the Children's Workforce Development Council (2007, p. 3) stated:

High quality supervision is one of the most important drivers in ensuring positive outcomes for people who use social care and children's services. It also has a crucial role to play in the development, retention and motivation of the workforce.

The intense, emotional work of social care, together with its bureaucratic challenges, cannot be overstated. The need for greater opportunities for pedagogical conversations, and person-centred support and leadership, is desired and valued by the professionals in the field (Fabianowska \& Hanlon, 2014). 


\section{A combined leadership approach in social care management}

The Victoria Climbié Inquiry stated 'that a healthy culture begins with high quality leadership' where managers 'walk the talk' and endeavour to listen fully to understand the issues facing front-line staff (Laming, 2003, p. 15). Walker (2008) states that one of the key functions of an organisation is to act as a secure base, as the more secure a social care worker feels about their organisation, the more likely they will be able to do their work well. This requires social care managers to be able to create a positive, safe, learning culture. Individual responsibility has to be recognised but there needs to be a willingness to learn from mistakes, take calculated risks and start again (Fenton, 2015). In this context, performance measures become a means of self-improvement (Laming, 2003). A report by the Ombudsman for Children in Ireland (2013) highlighted that best practice in residential care is a culture that supports resilient workers who will work with children through difficult times. The aforementioned public inquiries and case reviews in the UK have specifically highlighted failures in leadership to provide this secure base for social professionals in the messy and ambiguous work of social care, which unlike many other professions cannot be fully risk avoidant (Walker, 2008).

Munro (2011) highlighted the importance of leadership to facilitate workers to utilise their professional judgement and to embrace the workers' capacity to be skilled in relationships. This reflective and relationship-based practice should be embraced by social care managers (Munro, 2010) and can be achieved through effective leadership. There are many debates about the nature and style of leadership, its definition and its impact within the social professions (Hafford-Letchfield et al., 2014). Thus, there is a strong case to be made for the use of a combination of leadership approaches (transformational, situational and shared) along with pedagogical leadership in social care practice in Ireland.

Current observation suggests that common leadership practice in health and education in the UK and Ireland is of a transactional nature (Hafford-Letchfield et al., 2014). Transactional leadership is an approach that capitalises on stability and has a strong hold on maintaining the status quo and steering the way ahead (HaffordLetchfield et al., 2014). Such leaders are therefore forced into procedures such as increasing the efficiency of established routines and procedures concerned with establishing and standardising practices that will help the organisation reach maturity, productivity and efficiency (Hafford-Letchfield et al., 2014). 
In contrast to a transactional style, a transformational leader engages more actively with the team by focusing on higher-order, intrinsic needs and raising consciousness about the overall mission, inspiring a vision for staff that motivates them to achieve that vision, the significance of specific outcomes and new ways these might be achieved (Lynch et al., 2011). Such leaders will put the group needs first, by connecting the team's identity with the organisation's identity. These leaders are said to provide an inspirational role based on trust, admiration, loyalty and respect from the team, who are in turn willing to commit as a direct result of the leader's capacity for emotionally intelligent behaviour (Hafford-Letchfield et al., 2014). Lynch et al. (2011) suggest that leaders need to work with their teams to develop a shared vision for person-centredness. Once a leader has clarified and shared the vision, he or she can focus on responding to the needs of the people, understanding that their role is to remove barriers to achieve that vision.

Situational leadership (Hersey \& Blanchard, 1982) provides a responsive model of leadership, where the leader adjusts their style (or response) to the needs of the worker (or learner). This type of leadership, observed in a social care setting in Dublin, has helped successfully transform a restrictive institution to a vibrant community of older adults (Lynch et al., 2011). The core components of situational leadership are the leader's ability to diagnose the performance, competency and commitment of each member of the team. The leader's response and guidance is based upon the needs or level of direction required by the team member, ranging from directing, guiding, supporting and delegating behaviours. Baxter et al. (2014) report on the success of this approach to leadership in North America and particularly within the educational and child care sectors.

Distributed or participatory leadership is where the leader seeks to share power and work in the most democratic way. In this capacity, leadership is not associated with a specific position but is instead an attribute assigned to different individuals throughout the organisation, focusing on leadership practice more so than roles (HaffordLetchfield et al., 2014).

Sergiovanni (1998) first presented pedagogical leadership (sometimes referred to as educational or instructional leadership) as a leadership style that aims to develop human capital. The term pedagogy may be understood as a set of practices or philosophical underpinnings that shape organisations around learning in order to meet externally applied standards and expectations of practice. This 
approach to leadership may be very relevant to the bureaucratic profession of social care, where leadership is integrated as an overarching process for effective functioning of the organisation (Male \& Palaiologou, 2015). While Sergiovani was exploring pedagogical leadership, Wenger (1998) also recognised the crucial role of learning within communities of practice in the development of organisations. Therefore, it would seem that the combination of these two approaches would be complementary. Although 'connections between pedagogical leadership and distributed leadership have not yet been explored fully... there is research to support connections between shared thinking of [practitioners'] roles and responsibilities and success in pedagogical leadership' (Heikka \& Waniganayake, 2011, p. 508).

Pedagogical leadership is embedded in the leadership and relational literature. It is a social constructivist approach that is collaborative, reciprocal and respectful, while enhancing both personal and professional relationships. It encourages critical reflection and inquiry on behalf of the leader and 'supports reflective practitioners to think about situations and relationships, bring[ing] theories to bear on these, decid[ing] how to proceed and review[ing] the results of their actions' (Moss, 2006, p. 143). Andrews (2009) suggests the emphasis of this approach is focused on team and individual skill development that will lead to and support organisational change. Karila (as cited in Heikka \& Waniganayake, 2011) expanded this concept of leadership, proposing that the focus moves away from management tasks and into the shared or distributed leadership realms.

We argue that a pedagogical approach to leadership would be beneficial for social care practice, where leaders would facilitate opportunities for staff to examine their professional beliefs, responsibilities and actions in order to provide quality decisionmaking and care. Pedagogical leadership does not absolve the leader from their supervisory or management responsibilities, but it does help create a workplace culture that allows for honest and ethical conversations about practice, while empowering staff to take responsibility for their actions (Cheliotes \& Reilly, 2012).

Pedagogical leaders support learning and relationship development through the creation of a trusting and supportive work environment that encourages dialogue and reflection. As pedagogical leaders, social care managers would facilitate the creation of a learning organisation (or community) where an important focus of their work with staff is about social care pedagogy. Although social care is a bureaucratic 
profession where managers are primarily answerable to legislation and policy created at a state level, the pedagogical process supports team work, mentoring and coaching, allowing an organisation 'to tackle changes, to develop its vision and a new experience of learning based on sharing knowledge... and practice, and providing unconditional access to continuously changing resources for all participants, through collaboration and cooperation, in an atmosphere of openness and trust' (Male \& Palaiologou, 2012, p. 112).

Pedagogical leaders possess an authentic desire to support professional growth and recognise that time spent in dialogue is critical. They are knowledgeable about their practice and have developed a keen self-awareness and the ability to honestly reflect. These leaders have well-developed observation skills and are strong communicators, with good listening and reflective questioning skills (Cheliotes \& Reilly, 2012). The pedagogical leader's role is to accompany the learners in their learning process, to help them to become conscious and reflective of their own wisdom (Heikka \& Waniganayake, 2011).

Baxter et al. $(2013 ; 2014)$ have experienced positive success with the use of coaching conversations as a process to support pedagogical leaders in their work with learning communities. This coaching process begins with some observation and documentation of an action or event or with a child and/or youth. Documentation may be in the form of a learning story, case notes or journaling. Reflection of the experience may occur in conjunction with the writing process and be then shared with the team, where dialogue and conversation is facilitated by the leader. The leader poses thoughtfully constructed questions, such as 'What is to be learned from a particular incident? Is there a body of theory that might help us understand better? Or what are the implications for now and future work?' (Cheliotes \& Reilly, 2012, p. 99), to encourage further reflection and discussion. These thought-provoking questions move from the consideration of details surrounding the event to the 'big' idea that helps the team members to explore their own understanding and actions within a similar context. This process allows for the group to appropriately challenge traditional practices and contradictions, without focusing on the individual, and to identify the results or changes they would like to build into their work.

Throughout the coaching facilitation, the pedagogical leader avoids giving advice, judging, sharing how they feel and/or describing what they might have done in a similar situation. According to Cheliotes \& 
Reilly, the leader should pay close attention to verbal and non-verbal cues: tone, body language and silence. These authors suggest the leader should help the speaker clarify their thinking, through the use of exploratory questions and listening intently. The process then typically includes a summary about what the person has shared and then the facilitation of a conversation with reflective questioning, such as 'Is there another way to solve this problem? I wonder what would happen if...? [or] What would you do differently as a result of your insight?' (2012, p. 99). The belief is that by posing key questions and possibilities, the participants will learn, through self-reflection, the perspectives of others and build critical thinking skills and abilities that will support them in their practice. The strengths of adopting this pedagogical practice are increased confidence and competence within the team (Cheliotes \& Reilly, 2012).

Challenges with this type of pedagogical approach may include creating the time and learning-culture 'space' to engage in reflective and critical ways of knowing. Often because of too many competing demands and expectations, time for leading pedagogical conversations is minimised. Some leaders have also expressed difficulty keeping the conversations going through the generation of questions - without knowing or providing all of the answers (Baxter et al., 2014). Also, 'to be effective, distribution of pedagogical leadership has to be assessed against different aspects of leadership, including the separation of management and leadership functions' (Heikka \& Waniganayake, 2011, p. 509).

The need for pedagogical conversations is no stronger than in residential child care. Howard (2012, p. 38) suggests the incessant demands of bureaucracy mean that children exist in artificial, sanitised care bubbles where they are bereft of structure, empathy, spontaneity and real relationships. The very things they crave.' He suggests that ever-increasing demands on social care workers' time mean that more time will be spent writing about children and reporting on them rather than actually caring for them (Howard, 2012). The reports from the UK could suggest his fears may be realised if we don't continue to review the Irish situation and begin a new way of working.

It is argued that a pedagogical approach, along with a combination of facets of transformational and situational leadership styles, can be a valuable approach to support the social care manager as they guide practitioners in the twenty-first century. Leaders who possess this combination of leadership approaches and skills will be able to facilitate a shared vision, supervise within a situational and responsive 
nature, foster learning and reflection through the use of coaching conversations as a way to support the complexity of the practice, and balance accountability with a refocus towards the practice of care.

\section{Conclusions and remarks about leadership in the Irish social care context}

Featherstone et al. argue that England's difficulty is Ireland's opportunity, whereby in recent times England has emphasised regulating over provision where a 'central elite know best' (2012, p. 50). Their reform of children's services was accelerated following the aforementioned report about the death of Victoria Climbié, which prompted the highly influential inquiry into professional and institutional failure (Laming, 2003). Their system was not working to support safe practice. Social care work in Ireland should not make the same mistake. Damaging relationships with adults is the primary reason for many young people experiencing difficulty. Therefore, maintaining a focus on pedagogy and relationships holds the potential for the young person to restore trust in a safe relationship with a trusted adult (Trevethick, 2003).

No social care worker or manager wants to be a 'bureau-carer' or a 'care-technician' solely carrying out administrative functions (Fenton, 2015, p. 171). Social care workers need the time, space, argumentative flexibility, analytical ability and trusting relationships in order to be able to debate and make sense of what is reported and recorded within the possible increased demands of documentation required in their role. 'Managers need to decide what should be strictly regulated and what should be left to empowered individuals and groups' (Featherstone et al., 2012, p. 53). This discernment, as evidence suggests, may be best achieved through pedagogical approaches to leadership.

It is envisaged that pedagogical leadership will give leaders and their teams a reflective space with peers to explore and examine practice in order to provide the quality and caring service they wish to provide (Fenton, 2015). The incorporation of the use of a variety of leadership approaches (i.e. transformational, situational and pedagogical) is a means of viewing new ways to work with social care workers, respecting them as intellectuals, and acknowledging the complexity of the practice and responsibility (Male \& Palaiologou, 2012).

It is this type of combined leadership that might fit with what Wastell (2011) calls socio-technical systems design (STSD), where 
work environments are open, comprising two sub-systems: the 'technical and the social'. STSD strives for optimal balance of these two subsystems, where leaders basically do not overspecify, delegate as much as safety and accountability will allow, and liberate people to innovate and adapt to unpredictable situations (Featherstone et al., 2012). This is the epitome of STSD: complex jobs and simple organisation.

In this article, it has been argued that Ireland should grasp the opportunity to embrace principles of system design which aim to build trust and support the front-line professional task, 'guarding against the seductive proxies for quality that timescales and targets produce' (Featherstone et al., 2012, p. 60). Global human service work partners could experience success in creating balance between pedagogical approaches and regulatory demands, with the use of combined leadership approaches to build trust and confidence in the social care sector.

There is no doubt that registration, regulation and inspection/ monitoring regimes have brought about significant benefits to social care for children and adults since the introduction of the SSI, and now more recently HIQA, most notably in eliminating the abuse that formerly occurred within residential settings (Fenton, 2015). However, Francis (2013) believes the regulators also need support from strong leaders to bring about a shift in culture and put the effective care of people by committed and compassionate staff at the heart of the standards. In fact, HIQA (2013) stated that the quality of residential services is almost entirely dependent on the commitment and quality of the staff team and its leadership. As Banks (2006) states, it is our values that will influence how we interpret regulations and the law.

A broad introduction has been presented in this article to address some of the critical debates around the impact of increased bureaucracy in this new era of professionalisation in social care. By drawing on the literature, the complexity of the issues and the critical need for effective leadership have been identified. The effectiveness of first-line managers can have a crucial impact on service quality in health and social care; however, it is only through internal leadership, public scrutiny and policy development with stakeholders working together towards a common vision that we can create sustainable, effective and compassionate change within the Irish social care sector. 


\section{References}

Andrews, M. (2009). Managing change and pedagogical leadership. In A. Robins and S. Callan (Eds), Managing early years' settings: Supporting and leading teams (pp. 45-64). London: Sage Publications.

Balloch, S., Pahl, J., \& McLean, J. (1998). Working in the social services: Job satisfaction, stress and violence. British Journal of Social Work, 28 (3), $329-50$.

Banks, S. (2006). Ethics, accountability and the social professions. London: Palgrave Macmillan.

Banks, S. (2007). Between equity and empathy: Social professions and the new accountability. Social Work and Society, 5, 11-22.

Barry, U., \& Conlon, C. (2010). Elderly care in Ireland - Provisions and providers. UCD School of Social Justice Working Papers, 10 (1), 1-34.

Basu, R. (2004). Public administration: Concepts and theories (5th ed.). New Delhi: Sterling Publishers.

Baxter, J., Carston, C. S., \& Farebrother, M. (2013). Phase 1 - Early learning and child care pilot project: A report for the Alberta Ministry of Human Services. Calgary, Alberta: Mount Royal University.

Baxter, J., Carston, C. S., \& Farebrother, M. (2014). Phase II - Early learning and child care pilot project: A report for the Alberta Ministry of Human Services. Calgary, Alberta: Mount Royal University.

Beresford, P. (2014, August 7). Bureaucracy and bad management are changing social work. The Guardian.

Burck, C., \& Cooper, A. (2007). Introduction: Dialogues and developments in social work practice: Applying systemic and psycho-analytical ideas in the real world. Journal of Social Work Practice, 21 (2) 193-96.

Burns, K., \& McCarthy, J. (2012). An impossible task? Implementing the recommendations of child abuse inquiry reports in a context of 'high' workloads in child protection and welfare. Irish Journal of Applied Social Studies, 12 (1), 25-37.

Cheliotes, L. G., \& Reilly, M. (2012). Opening the door to coaching conversations. Thousand Oaks, CA: Sage Publications.

Commission to Inquire into Child Abuse. (2009). Report of the commission to inquire into child abuse. Dublin: The Stationery Office.

Davis, K., \& Mullender, W. (1993). Ten turbulent years: A review of the work of the Derbyshire coalition of disabled people. Nottingham: Nottingham Centre for Social Action, School of Social Studies, University of Nottingham.

Dent, M., \& Whitehead, S. (2002). Introduction: Configuring the 'new' professional. In M. Dent \& S. Whitehead (Eds), Managing professional identities: Knowledge, performativity and the 'new' professional (pp. 127-64). London: Routledge.

Department of Children, School and Families. (2010). Working together to safeguard children: A guide to inter-agency working to safeguard and promote the welfare of children. Retrieved from http://webarchive.nationalarchives. 
gov.uk/20130401151715/https://www.education.gov.uk/publications/eorderi ngdownload/00305-2010dom-en-v3.pdf [10 July 2016].

Department of Health. (2011). Future health: A strategic framework for reform of the health service 2012-2015. Dublin: Department of Health.

Fabianowska, J., \& Hanlon, N. G. (2014). Emotional labour in harm-reduction practice in Ireland: An exploratory study. Irish Journal of Applied Social Studies, 13 (1), 53-65.

Featherstone, B., White, S., \& Wastell, D. (2012). Ireland's opportunity to learn from England's difficulties? Auditing uncertainty in child protection. Irish Journal of Applied Social Studies, 12 (1), 49-60.

Fenton, M. (2015). Social care and child welfare in Ireland: Integrating residential care, leaving care and aftercare. Dublin: Liffey Press.

Francis, R. (2013). The Mid-Staffordshire NHS Foundation Trust public inquiry. London: The Stationery Office.

Gallagher, C., \& Kennedy, K. (2003). The training implications of a social care approach to working with older people. Irish Journal of Applied Social Studies, 4 (1), 77-95.

Garfat, T. (2001). New beginnings. Irish Journal of Applied Social Studies, 2 (3), 31-5.

Gray, I., Field, R., \& Brown, K. (2010). Effective leadership, management and supervision in health and social care. Exeter: Learning Matters.

Hafford-Letchfield, T., Lambley, S., Spolander, G., \& Cocker, C. (2014). Inclusive leadership in social work and social care. Bristol: Policy Press.

Heikka, J., \& Waniganayake, M. (2011). Pedagogical leadership from a distributed perspective within the context of early childhood education. International Journal of Leadership in Education, 14 (4), 499-512.

Hersey, P. K., \& Blanchard, K. (1982). Management of organisational behaviour (4th ed.). Englewoods Cliff, NJ: Prentice Hall.

HIQA. (2010). Draft national standards for child protection and welfare. Dublin: The Stationery Office.

HIQA. (2013). Overview of findings of 2012 children's inspection activity: Foster care and children's residential services. Dublin: The Stationery Office.

Howard, N. (2012). The Ryan report (2009): A practitioner's perspective on implications for residential child care. Irish Journal of Applied Social Studies, 12 (4), 38-47.

Howard, N. (2014). The Irish association of social care workers. In N. Howard \& D. Lyons (Eds), Social care: Learning from practice (pp. 12-23). Dublin: Gill and Macmillan.

HSCIC. (2014). Busting bureaucracy: Collaborative audit findings and recommendations. London: The Stationery Office.

HSE. (2011). Time to move on from congregated settings: A strategy for community inclusion. Retrieved from http://www.hse.ie [6 July 2016].

International Federation of Social Workers. (2010). Standards in social work practice meeting human rights - The basis for a common framework of standards in social work practice in Europe. Berlin: IFSW European Region. 
Irish Association of Social Workers. (2011). Call for change discussion document: Children and families social workers make their voices heard. Dublin: The Stationery Office.

Johnston, S. C., Cooper, C., Cartwright, I., Taylor, D. P., \& Millet, C. (2005). The experience of work related stress across occupations. Journal of Managerial Psychology, 20 (2), 178-87.

Killeen, A. (2014). Achieving independent living for people with disabilities. In N. Howard \& D. Lyons (Eds), Social care: Learning from practice (pp. 94-107). Dublin: Gill and Macmillan.

Lalor, K., \& Share, P. (Eds). (2009). Applied social care: An introduction for students in Ireland (2nd ed.). Dublin: Gill and Macmillan.

Lalor, K., \& Share, P. (2013). Understanding social care. In K. Lalor \& P. Share (Eds), Applied social care: An introduction for students in Ireland (3rd ed.). Dublin: Gill and Macmillan.

Laming, L. (2003). The Victoria Climbié inquiry report. London: The Stationery Office.

Laming, L. (2009.) The protection of children in England: A progress report. London: The Stationery Office.

Lenihan, E., \& Sweeney, J. (2010). Measuring levels of burnout among care workers. Learning Disability Practice, 13 (8), 27-33.

Lloyd, C., King, R., \& Chenoweth, L. (2002). Social work, stress and burnout: A review. Journal of Mental Health, 11 (3), 255-66.

Lynch, B., McCormack, B., \& McCance, T. (2011). Development of a model of situational leadership in residential care for older people. Journal of Nursing Management, 19, 1058-69.

Male, T., \& Palaiologou, I. (2012). Learning-centred leadership or pedagogical leadership? An alternative approach to leadership in education contexts. International Journal of Leadership in Education, 15 (1), $107-18$.

Male, T., \& Palaiologou, I. (2015). Pedagogical Leadership in the 21st century: Evidence from the field. Educational Management Administration and Leadership, 43 (2), 214-31.

McCarthy, B. (2006). Organisational stress in social care [Doctoral thesis]. Retrieved from arrow.dit.ie [6 July 2016].

Mendes, L., \& Fradique, M. J. J. (2013). Influence of nursing leadership on quality nursing care. International Journal of Health Care, 27 (5), 439-50.

Mesabbah, M., \& Arisha, A. (2016). Performance management of the public healthcare services in Ireland: A review. International Journal of Health Care Quality Assurance, 29 (2), 209-35.

Moss, P. (2006). Structures, understanding and discourses: Possibilities for reenvisioning the early childhood worker. Contemporary Issues in Early Childhood, 7, 30-41.

Moyle, W., Venturio, L., Cooke, M., Hughes, J., \& VanWyks, M. (2013). Promoting value in dementia care: Staff, resident and family experience of 
the capabilities model of dementia care. Aging Mental Health, 17 (5), 587-94.

Munro, E. (2010). The Munro review of child protection. Part 1: A systems analysis. London: The Stationery Office.

Munro, E., (2011). The Munro review of child protection. Final report: A childcentred system. London: The Stationery Office.

National Disability Authority. (2011). The introduction of individual budgets as a resource allocation system for disability services in Ireland. Dublin: Department of Health.

O'Donovan, M. (2015). The challenges of distributing leadership in Irish postprimary schools. International Electronic Journal of Elementary Education, 8 (2), 243-66.

Ombudsman for Children. (2013). A meta-analysis of repetitive root cause issues regarding the provision of services to children in care. Retrieved from http://www.oco.ie/wp-content/uploads/2014/03/OCOMeta-analysisof servicesforchildrenincare.pdf [6 July 2016].

Sergiovanni, T. J. (1998). Leadership as pedagogy, capital development and school effectiveness. International Journal of Leadership in Education, 1, $37-46$.

Skills and Labour Market Research Unit. (2009). Monitoring Ireland's skill supply. Dublin: The Stationery Office.

Skills for Care and the Children's Workforce Development Council. (2007). Providing effective supervision. London: Stationery Press.

Smith, M. (2009). Rethinking residential child care. Bristol: The Policy Press.

Smith, M. (2016, April). Considering care. Paper presented at the annual conference of Social Care Ireland, Naas, Co Kildare.

Smyth, E., Healy, O., \& Lydon, S. (2015). An analysis of stress, burnout and work commitment among disability support staff in the UK. Research in Developmental Disabilities, 47, 297-305.

Trevethick, T. (2003). Effective relationship-based practice: A theoretical exploration. Journal of Social Work Practice, 17 (2), 163-76.

Walker, D. (2008). Communication and social work from an attachment perspective. Journal of Social Work Practice: Psychotherapeutic Approaches in Health, Welfare and the Community, 22 (1), 5-13.

Wastell, D. (2011). Managers as designers in the public services: Beyond technomagic. Devon: Triarchy Press.

Wenger, E. (1998). Communities of practice: Learning, meaning and identity. Cambridge: Cambridge University Press. 